\title{
Investigation of Compositional Effects of Virgin and Recycled HDPE on Mechanical Properties of Pipe
}

\author{
Solomon Tesfaw ${ }^{1}$, Olawale Samuel Fatoba ${ }^{2 *}$; Teshome Mulatie ${ }^{3}$; Ester Titilayo Akinlabi ${ }^{4}$, \\ ${ }^{1}$ Department of Mechanical Engineering, Debre Tabor University, Debre Tabor, Ethiopia. \\ ${ }^{2}$ Department of Mechanical Engineering Science, University of Johannesburg, Johannesburg., South Africa. \\ ${ }^{3}$ Department of Mechanical Engineering, Bahir Dar Institute of Technology, Bahir Dar University, Bahir Dar, Ethiopia. \\ ${ }^{4}$ Pan African University for Life and Earth Sciences Institute (PAULESI), Ibadan, Nigeria
}

\begin{abstract}
Nowadays, High-Density Polyethylene (HDPE) polymers are widely being used and its products are preferable than metals having the properties such as lightweight, ease of manufacture, stronger and tough. This makes HDPE polymers as the top choice by manufacturers. However, one of the drawbacks is that this polymer takes time to decay and affects the environment when this material is disposed as wastes. Almost all industries use only virgin imported materials to produce HDPE pipe and fittings, and this leads to increase in manufacturing cost and extraction of virgin material. The aim of this research is to overcome this problem by recycling process. This research work focuses on investigating the compositional effects of virgin and recycled HDPE on the mechanical properties of HDPE pipe fitting. The mixing of recycled with virgin (pure) HDPE were done at different weight percentages (0:100, 10:90, 20:80, 30:70, 40:60, 50:50, 60:40, 70:30, 80:20, 90:10, and 100:0). In this work, $16.5 \mathrm{~kg}$ virgin HDPE were used, and $16.5 \mathrm{~kg}$ recycled HDPE pellets were prepared. Also, 11 (eleven) T-reducer pipe fitting samples were produced via injection moulding machine. Melt flow rate and ash content of the manufactured recycled materials were tested to determine the quality of the plastics. Tensile strength test was also conducted to investigate the mechanical property in order to determine the percentage which possess the optimum strength. From the experimental results, recycled contents up to $70 \mathrm{wt}$. \% and virgin contents up to $30 \mathrm{wt}$. \% by mass were found to meet the standard requirements. This optimum proportion will help AG Pipe fitting company to save a lot in dollars every year by using the scrap contents.
\end{abstract}

\section{Introduction}

High demand of advanced military technology during the WWII forced U.S and Germany to develop and investigate new types of polymers. Such as polyvinyl chloride, polystyrene, polyethylene, polypropylene, polyesters, and polyurethanes. Expansion of the petrochemical industry in the twentieth century gave a rise to the many plastics types, and their many applications [1-6]. Since the use of these plastics is continuously increasing, the problem of post-consumer recycling of these materials has become an important issue for economic and environmental reasons. However, in contrast to glass and metals, which can be recycled into products with properties essentially similar to those of the primary materials, each time polymers are reprocessed, they lose some of their physical and mechanical properties because of peroxidation [7].

Due to the ease of manufacturing, durability and low cost of plastics, they find increasing use in the manufacture of several types of consumer and industrial product such as in packaging, house hold consumer durables, electrical appliances, shipping containers, pipe sidings, toys and etc.(Lin et al., 2015). Also, with the price of petroleum increasing rapidly, plastic wastes are becoming of more interest as an inexpensive source of raw materials [9]. The worldwide production of plastics is approximately 100 million tons per annum, resulting in a significant proportion in municipal solid waste (MSW) [1]. It is believed that the management of solid waste is one of the major environmental concerns in the world. Due to limited space on landfills and increasing costs of plastics, utilization of waste plastics has become an attractive alternative for disposal [10]. Consequently, with growing public concern about environmental issues, plastic waste recycling offers a top shot solution [11]. Unlike metals, polymers generally are characterized by a lower density, strength, elastic modulus, thermal and electrical conductivity, and cost. Also, by a higher strength-to weight ratio, resistance to corrosion, thermal expansion, wider choice of colors and transparencies; and by a greater ease of manufacture. Hence, plastics are being used mostly in agriculture, clothing, construction and other fields which required their existence [2]. High-Density Polyethylene (HDPE) is most common and thermoplastic polymer. It can be melted to a liquid and remolded it to a solid state [12]. It is used in numerous applications ranging from plastic grocery bags

\footnotetext{
* Corresponding author: proffatobasameni@gmail.com
} 
to heavy duty plastics containers and widely been used in construction industry for producing pipes. Wastes of recyclable materials like paper, plastic, glass, and metal would rather be used as raw materials instead of being buried in disposal areas. In this manner, use of recycled materials will reduce the quantities sent to landfills, as well as reducing raw material extraction. The largest fraction of waste is mainly composed of polyolefin, such as PE and PP (60-70\%) and the remaining include PS (10-15\%), PVC (15\%), and PET (5\%) [13].

Improper and uncontrolled plastics production and consumption causes wastes, this vast waste stream that reaches each year to the final recipients creating a serious environmental problem. Because their decay process takes a very long time [14]. The presently most common practice of handling such waste streams is to incinerate them with energy recovery or to use them for landfilling. Relevant statistics showed that the Disposing of the waste to landfill is becoming undesirable and plastic waste is harmful as its pigment contains many trace elements that are highly toxic [13]. One of the best options to manage the PSW is recycling and make it into new products rather than incineration to decrease the waste volume and environmental issue which reduced the HDPE wastes problem and the material consumption [15-20].

The consumption of virgin raw material in AG pipe fitting industry in Ethiopia were approximately 460 tons annually and it costs around 625 thousand dollars to import this raw material. The use of a certain amount of recycled material, will reduce the cost and consumption of imported materials. The aim of this research is to investigate the effect of recycled HDPE mixing ratio on the tensile strength of HDPE polymer and to reduce the consumption of virgin material and environmental pollution. Moreover, this investigation will show which of the mixing ratio of recycled and pure HDPE that are likely to improve the tensile strength property, by comparing to the tensile strength of pure HDPE.

\section{Methods and Materials}

The materials used for this research work were virgin high-density polyethylene (HDPE) and recycled HDPE materials with varying mixing ration based on their volume. The virgin resin is a black co-polymer, mainly being used for manufacturing different plastic products such as pipe. This raw material made from Saudi Arabia has an average particle size of $3.0 \mathrm{~mm}$ in diameter, and density of $0.9 \mathrm{~g} / \mathrm{cm} 3$, as shown in Figure 1. Recycled HDPE materials were obtained by sorting the waste by their identification tag (type 2) and crushing of HDPE products into small particle size and changes to pellet form produced through extrusion process before the actual experiment was carried out.

The flow of process for this study is illustrated in Figure 2 below. It is a visual representation of the sequence and give the whole picture of the study from the initial step (material collection) until the final step (testing of samples).

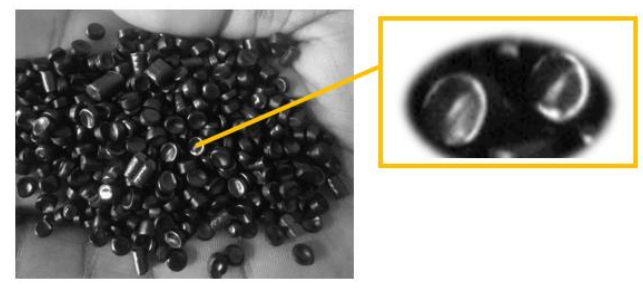

Fig. 1. virgin HDPE raw material

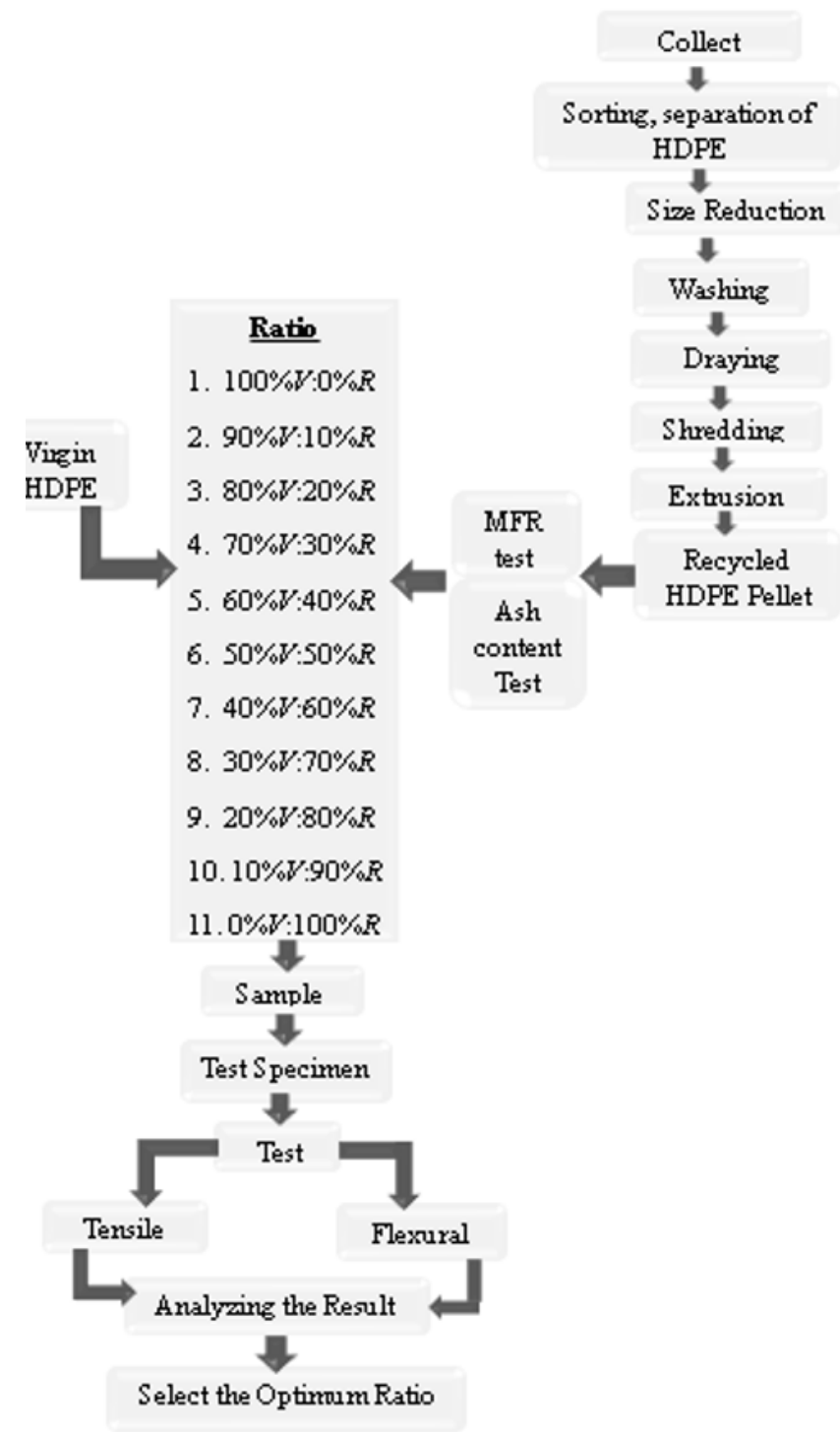

Fig. 2. Overall flow chart

\subsection{Collection and sorting}

Recycled HDPE were collected from different sources as shown in Figure 3. Post industrial waste and defect products were found on the scrap's storage. Sorting of the materials from other type is performed manually because it is easily detected by HDPE identification code number two. 


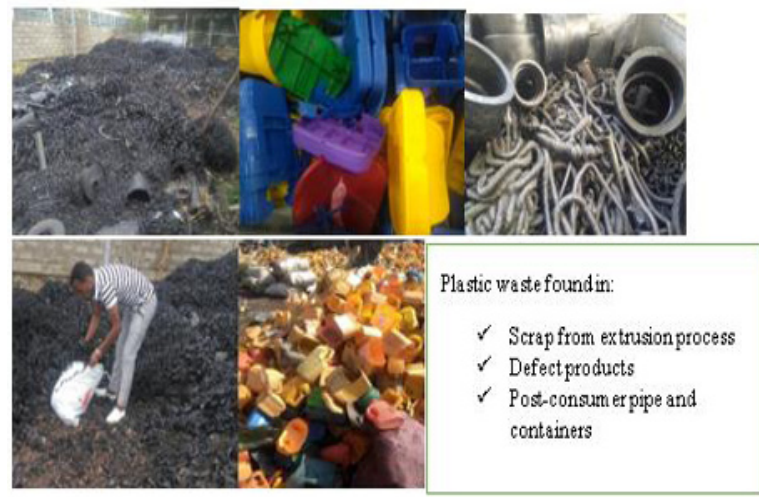

Fig.3. source of waste materials to be recycled

\subsection{Size reduction and Shredding}

Cutting of HDPE waste materials to reduce sizes which simply helps to easily crush by crushing machine is shown in Figure 4. The waste material is reduced in their size by band saw and jig saw machines before shredding, which are fed into the throat of the mill from the feed hopper and by means of gravitational effect it goes down as shown in Figure 4. The plastics enters the mill of the shredding machine, the teeth attached with the shaft of the machine is rotated and cutting plastics into small pieces/particles called flakes. Each plastic slowly reduced in size as particles are cutoff and moves outward into the narrow gap between the cutting faces and the flakes are collected through a 5-10 $\mathrm{mm}$ filter located at the bottom of the shredder to get an approximate uniform flake size shown in Figure 4 below.

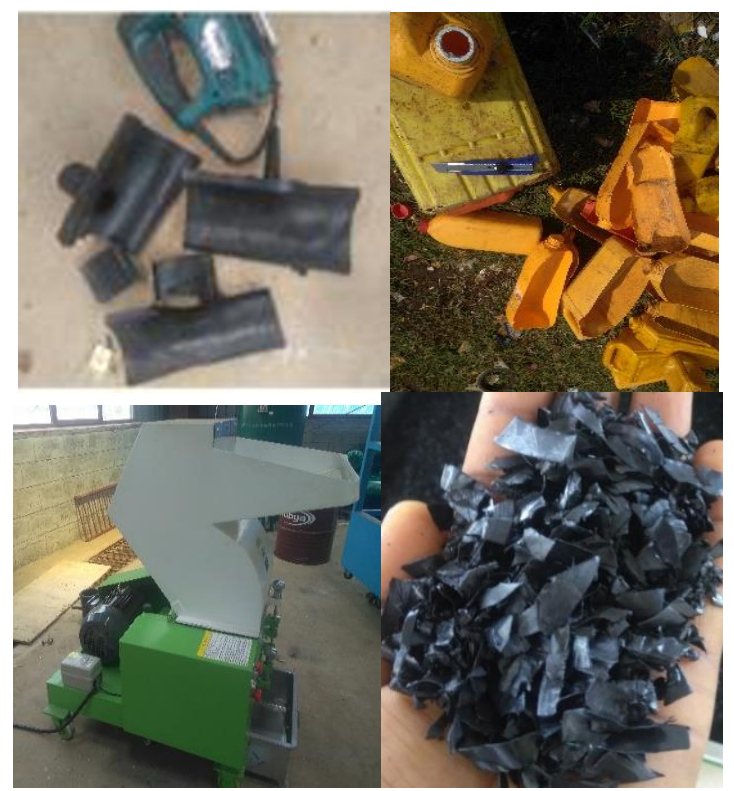

Fig.4. Suze reduction and Shredding of waste plastic

\subsection{Washing and Drying}

Waste HDPE materials were washed by hot water within a temperature around $600 \mathrm{C}$ for removing contamination from the flakes and other levels and glue attached on the material is removed by chemical washing. Berekina and detergents were used for washing the plastic flakes as shown in Figure 5. Waste materials were dehydrated before extrusion process was started. The materials were dried at ambient temperature for two days with the help of sunlight.

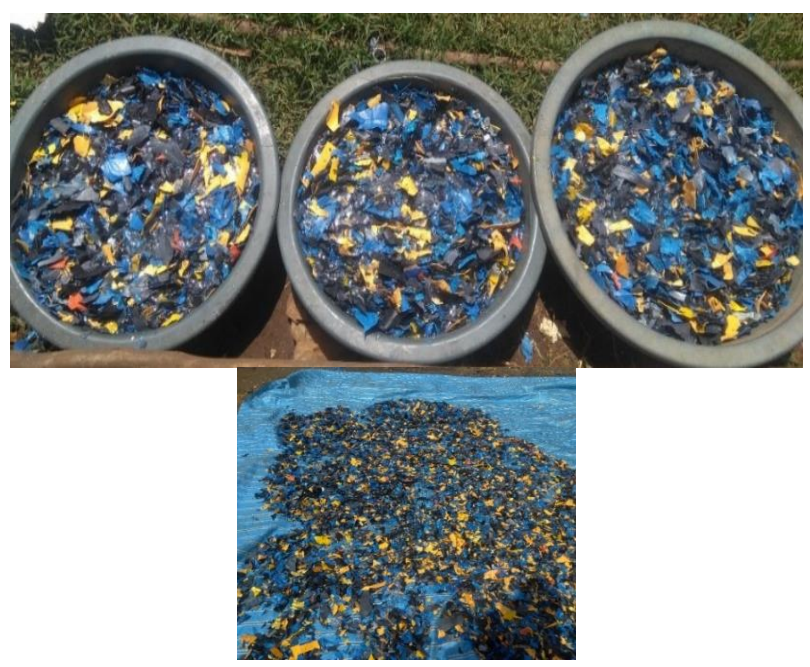

Fig.5. washing and drying washed plastic flake

\subsection{Extrusion and pelletizing}

The flakes were loaded into the KFM Eco Ex extruder hopper and then it was melted in the extrusion machine by the means of screw. The function of screw is either transporting the flakes or melting in different stages of temperature. There is a temperature sensor in every thermoset to read the values occurred at the stage of the screw. This process is started by feeding the plastic flakes which is shredded from a hopper into the barrel of the extruder. Then, the material is gradually melted. All the process parameter of extrusion of plastic flakes and methods were illustrated below in Figure 6 .

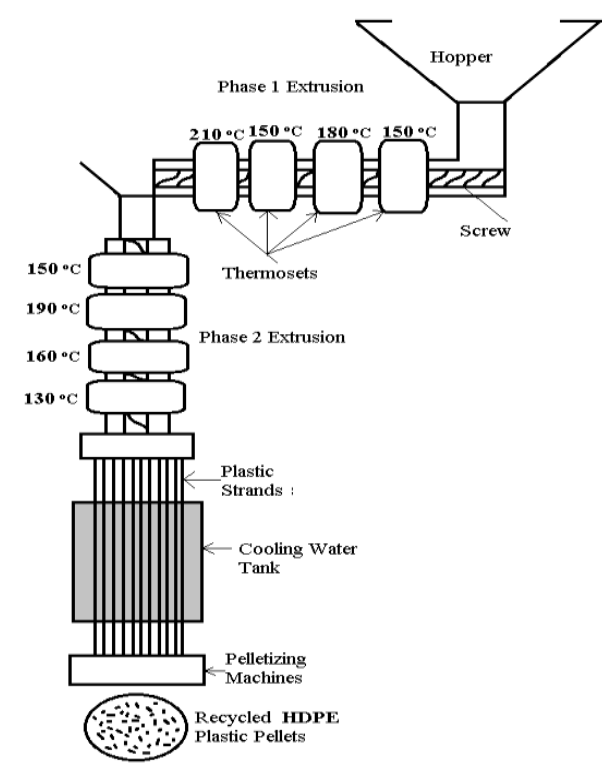

Fig 6: Schematic diagram of recycled Pellet production process 


\subsection{Quality Checking of rHDPE Pellet}

Plastic pellet manufacturing process has its own procedure of filtering impurities. In this study, quality tests on the amount of ash content and the flowability (melt flow rate) of the recycled pellets were used to determine the quality check.

\subsubsection{Ash content}

Ash test identifies the total filler content as shown in Figure 7. However, it cannot identify individual percentages in multi-filled materials without additional test procedures being performed. Also, an ash test cannot be used to determine the percent carbon fiber or percent carbon black since carbon burns off during the ash test. The test procedure conforms to ASTM D2584 standard.

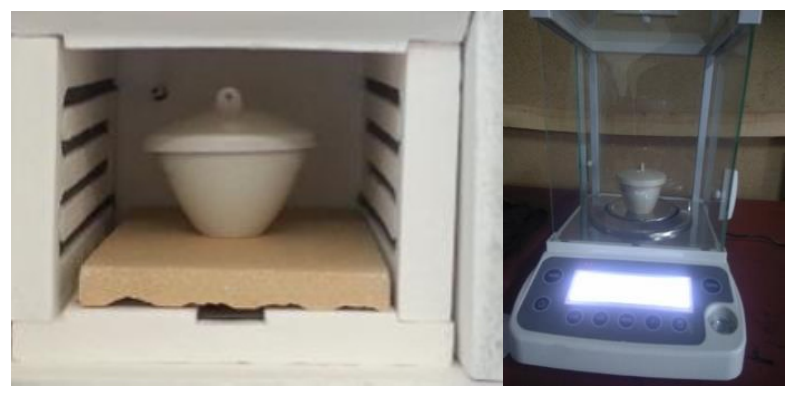

Fig. 7. Ash content test (a) Crucible in the furnace (b) measuring the mass of crucible and materials to be tested.

Twelve (12) grams of sample is typically used, which represents three crucibles each containing 4 grams of sample. Smaller sample weights can be tested but accuracy diminishes with smaller sample sizes. Typically, the average of three crucibles is reported as shown in Table 1.

Table 1. Test results of ash content test

\begin{tabular}{|c|c|c|c|c|}
\hline Temperature & $600^{\circ} \mathrm{C}$ & & & \\
\hline Time & $120 \mathrm{~min}$ & & & \\
\hline Sample ID & $\begin{array}{l}\text { Empty } \\
\text { Crucible } \\
\text { weight } \\
\text { (gram) }\end{array}$ & $\begin{array}{l}\text { With } \\
\text { Sample } \\
\text { weight } \\
\text { (gram) }\end{array}$ & $\begin{array}{l}\text { With Ash } \\
\text { crucible } \\
\text { weight } \\
\text { (gram) }\end{array}$ & $\begin{array}{l}\text { Ash } \\
\text { Mass } \\
(\%)\end{array}$ \\
\hline 1 & 71.2593 & 2.9062 & 71.3752 & 3.98 \\
\hline 2 & 71.5852 & 2.2575 & 71.6823 & 4.30 \\
\hline 3 & 70.7388 & 2.5626 & 70.8400 & 3.94 \\
\hline Average & & & & 4.06 \\
\hline
\end{tabular}

This means that the total filler or ash content is $3.98 \%$. The is due to the fact that the material is made of different HDPE plastics having different color, application and functions.

\subsubsection{Melt flow rate (MFR)}

Melt flow rate shown in Figure 8 measures the rate of extrusion of thermoplastics through an orifice at a prescribed temperature and load. It provides a means of measuring flow of a melted material which can be used to differentiate grades as with polyethylene or determine the extent of degradation of the plastic as a result of moulding. Degraded materials would generally flow more as a result of reduced molecular weight and could exhibit reduced physical properties. Typically, flow rates for a part and the resin it is moulded from are determined, and then a percentage difference is calculated. Alternatively, comparisons between "good" parts and "bad" parts may be of value.

Approximately 4 gram of the material is loaded into the barrel of the melt flow apparatus, which has been heated to a temperature specified for the material. A weight specified for the material is applied to a plunger and the molten material is forced to the die. A timed extrudate is collected and weighted. Melt flow rate values are calculated in $\mathrm{g} / 10 \mathrm{~min}$ as shown in Table 2.

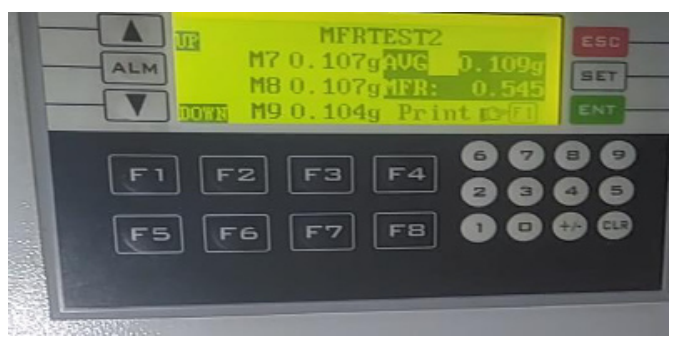

Fig. 8. Melt flow rate test

Table 2. Melt flow rate tested value of recycled HDPE

\begin{tabular}{|l|l|l|}
\hline Temperature & $\mathbf{1 9 0}$ & \\
\cline { 1 - 2 } Time & $\mathbf{1 2 0 s}$ & \\
\hline Sample ID & $\begin{array}{l}\text { Weight } \\
\text { (gram) }\end{array}$ \\
\hline 1 & 0.114 \\
\hline 2 & 0.113 \\
\hline 3 & 0.111 \\
\hline 4 & 0.110 \\
\hline 5 & 0.109 \\
\hline 6 & 0.107 \\
\hline 7 & 0.107 \\
\hline 8 & 0.107 \\
\hline 9 & 0.104 \\
\hline Average & 0.109 \\
\hline MFR & $0.545 \mathrm{~g} / 10 \mathrm{~min}$ \\
\hline
\end{tabular}

Test results obtained is within the recommended range of melt flow index value for recycled High density polyethylene materials, and the flowability of recycled HDPE is $0.545 \mathrm{~g} / 10 \mathrm{~min}$.

\subsection{Plastic Production}

In this research works, eleven samplings were taken in order to analyze the mechanical properties of virgin high density polyethylene (vHDPE) with some proportion of recycled high-density polyethylene (rHDPE) materials. The percentage indicates the quantity of HDPE scraps and virgin materials of PE100 in mass according to the capacity of the mold cavity. Blending of virgin and waste plastic sample was done in the ratio shown in Table 3. 
Table 3. Composition ratio in gram (g) and percent (\%)

\begin{tabular}{|c|c|c|c|c|c|c|}
\hline \multirow{2}{*}{$\begin{array}{l}\text { Samp } \\
\text { le } \\
\text { No. }\end{array}$} & \multicolumn{2}{|c|}{ In percent $(\%)$} & \multicolumn{2}{|c|}{ In gram $(\mathrm{g})$} & \multirow{2}{*}{$\begin{array}{l}\text { Sampl } \\
\text { e } \\
\text { Quanti } \\
\text { ty }\end{array}$} & \multirow{2}{*}{$\begin{array}{l}\text { Material } \\
\text { Consumpt } \\
\text { ion }(\mathrm{g})\end{array}$} \\
\hline & $\begin{array}{c}v \mathrm{HD} \\
\mathrm{PE}\end{array}$ & $\begin{array}{c}r \mathrm{HD} \\
\mathrm{PE}\end{array}$ & $\begin{array}{l}\nu \mathrm{HD} \\
\mathrm{PE}\end{array}$ & $\begin{array}{l}r \mathrm{HD} \\
\mathrm{PE}\end{array}$ & & \\
\hline 1 & 100 & 0 & 3000 & 0 & 1 & 3000 \\
\hline 2 & 90 & 10 & 2700 & 300 & 1 & 3000 \\
\hline 3 & 80 & 20 & 2400 & 600 & 1 & 3000 \\
\hline 4 & 70 & 30 & 2100 & 900 & 1 & 3000 \\
\hline 5 & 60 & 40 & 1800 & 1200 & 1 & 3000 \\
\hline 6 & 50 & 50 & 1500 & 1500 & 1 & 3000 \\
\hline 7 & 40 & 60 & 1200 & 1800 & 1 & 3000 \\
\hline 8 & 30 & 70 & 900 & 2100 & 1 & 3000 \\
\hline 9 & 20 & 80 & 600 & 2400 & 1 & 3000 \\
\hline 10 & 10 & 90 & 300 & 2700 & 1 & 3000 \\
\hline 11 & 0 & 100 & 0 & 3000 & 1 & 3000 \\
\hline \multicolumn{3}{|c|}{$\begin{array}{l}\text { Total material } \\
\text { consumptions }\end{array}$} & 16500 & 16500 & 11 & 33000 \\
\hline
\end{tabular}

After preparing the recycled HDPE pellet, the samples were manufactured. Both virgin and recycled HDPE raw materials were weighted through digital balance machine based on the mix ratio as shown in Figure 9.

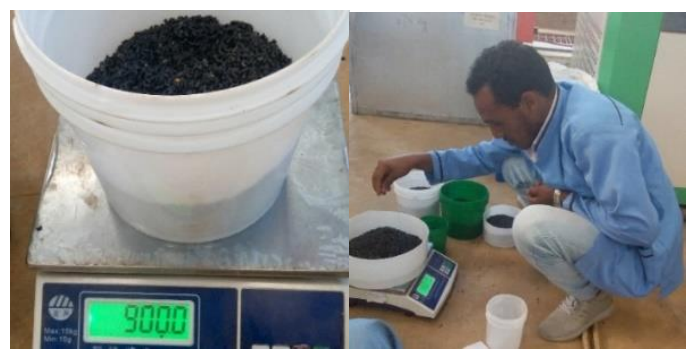

Fig. 9. Balancing the raw materials All the sample raw materials were measured based on the specified mix ratio as shown in Figure 10.

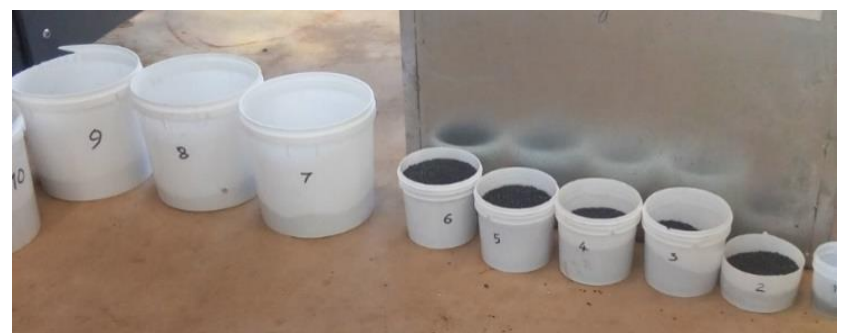

Fig. 9. Weighted raw materials for all samples

Before loading the raw materials into the hopper, mixing step is required for the blending of virgin HDPE and recycled HDPE materials according to the composition ratio as shown in Figure 11. The materials are loaded and mixing properly for about 15 minutes. The mixture of recycled and virgin HDPE material $(3 \mathrm{~kg})$ is loaded into the machine hopper via vacuum sucker to produce two T-Reducer HDPE fitting products including the allowable scrap and the materials remained on the screw.

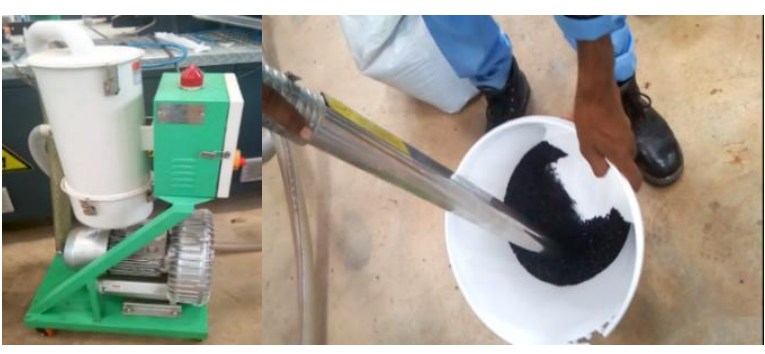

Fig. 11. Loading of mixed HDPE into hopper

Setup machines before feeding the raw materials is shown in Figure 12. This needs more time to heat the extrusion screw phases. The set values of the injection machine temperature ranges from $210 \mathrm{o} \mathrm{C}$ at the first phase of the screw to $230 \mathrm{oC}$ at the position of the final phase of the nozzle end. But the actual temperature which shows at the input screen is $2120 \mathrm{oC}$ at the first phase of the screw and $231 \mathrm{oC}$ at the end of nozzle. The cycle process for injection moulding is very short, typically for this part (T-reducer HDPE fitting 140×40).

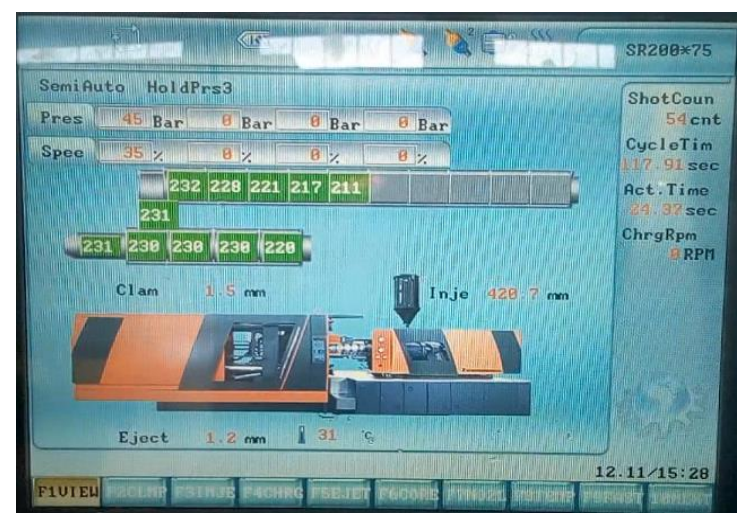

Fig. 12. The input values of machine setup Finally, all the sample parts were produced and identification code for separating the sample were stick on the parts as shown Figure 13.

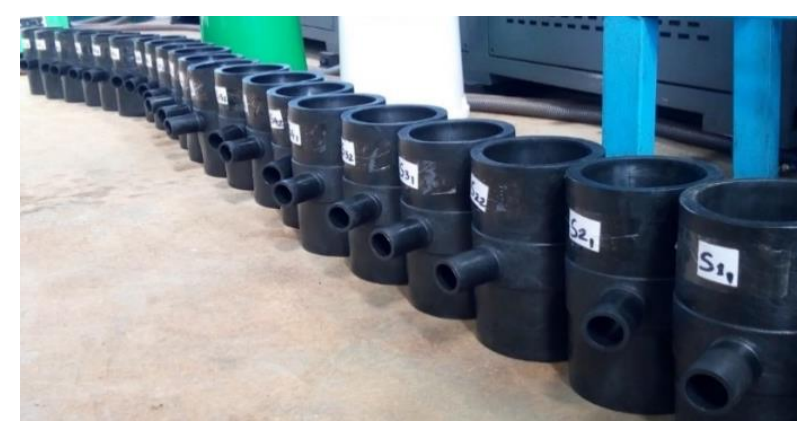

Fig. 13. Produced T-Reducer samples

\section{RESULTS AND DISCUSSION}

\subsection{Tensile test specimen}

According to ISO 527 standard test method for tensile properties of plastic Particularly ISO 6259-3 particularly for HDPE, its dog-bone tensile test specimen and detail dimension of the specimen data are given in Figure 14 and Table 4. respectively. 


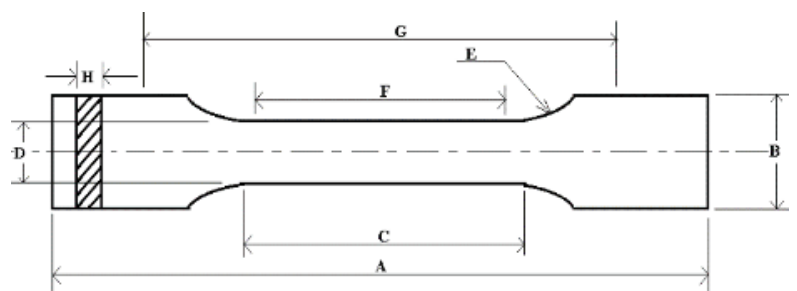

Fig. 14. Tensile test Specimen (Standard, 1997)

Table 4. Dimension of test specimen (Standard, 1997)

\begin{tabular}{|c|l|l|}
\hline Symbol & \multicolumn{1}{|c|}{ Description } & \multicolumn{1}{|c|}{$\begin{array}{c}\text { Dimension } \\
(\mathbf{m m})\end{array}$} \\
\hline A & Overall length (min.) & 150 \\
\hline B & Width of ends & $20 \pm 0.2$ \\
\hline C & $\begin{array}{l}\text { Length of narrow, } \\
\text { parallel-sided portion }\end{array}$ & $60 \pm 0.5$ \\
\hline D & $\begin{array}{l}\text { Width of narrow, } \\
\text { parallel-sided portion }\end{array}$ & $10 \pm 0.2$ \\
\hline E & Radius & 60 \\
\hline F & Gauge length & $50 \pm 0.5$ \\
\hline G & $\begin{array}{l}\text { Initial distance between } \\
\text { grips }\end{array}$ & $115 \pm 0.5$ \\
\hline H & Thickness & $\begin{array}{l}\text { That of the } \\
\text { pipe }\end{array}$ \\
\hline
\end{tabular}

All tensile test specimens prepared conformed to the standard and ready to test as shown in Figure 15.

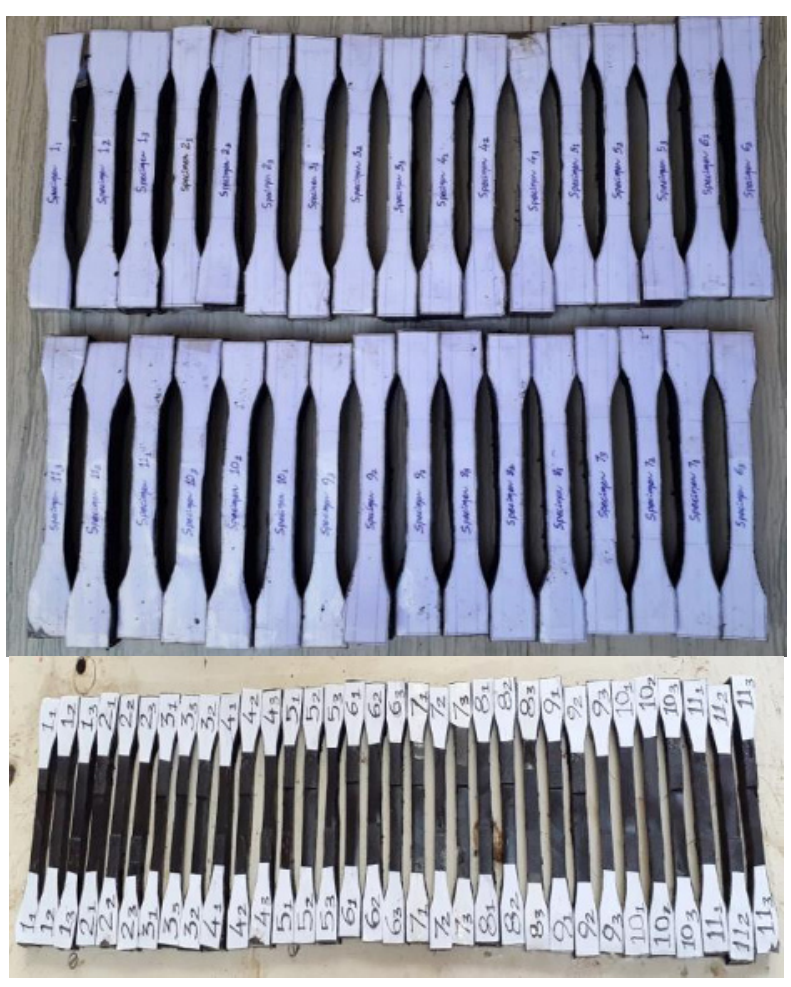

Fig. 15. All tensile test specimen

\subsection{Tensile Test results}

Tensile test was done according to ISO 527, specifically ISO 6259-1 type for HDPE. The experimental output was taken by direct reading from the test machine operating at room temperature and with a constant speed of $50 \mathrm{~mm} / \mathrm{min}$. The mean value of three specimens of each sample was taken. Each composition (sample) was tested using universal tensile test machine at Bahir Dar
Institute of Technology (BiT), material testing laboratory, Bahir Dar University, Ethiopia. The values of tensile strength $(\mathrm{MPa})$, elongation at break $(\mathrm{mm})$ and modulus of elasticity (MPa) were determined. Universal tensile testing machine is shown in Figure 16.

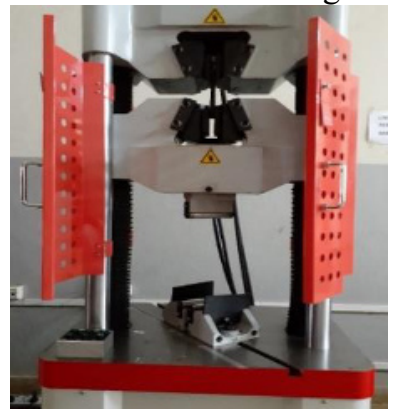

Fig. 16. Universal testing machine

Table 5 shows the vHDPE/rHDPE blend performance during the tensile tests for the $100 / 0$ ratio, while the yield strength, extension or elongation, ultimate tensile strength and other results are also listed in Table 5.

Table 5. vHDPE/rHDPE 100/0 mechanical property

\begin{tabular}{|c|c|c|c|c|c|c|c|}
\hline $\begin{array}{c}\text { Sample } \\
\text { No }\end{array}$ & $\begin{array}{l}\text { Cross } \\
\text { section } \\
\text { Area } \\
\left(\mathrm{mm}^{2}\right) \\
\end{array}$ & $\begin{array}{l}\text { Maximum } \\
\text { load (KN) }\end{array}$ & $\begin{array}{c}\text { Load } \\
\text { at } \\
\text { brake } \\
(\mathrm{KN}) \\
\end{array}$ & $\begin{array}{l}\text { Yield } \\
\text { stress } \\
\text { (Mpa) }\end{array}$ & $\begin{array}{c}\text { Ultimate } \\
\text { Tensile } \\
\text { stress } \\
\text { (Mpa) }\end{array}$ & $\begin{array}{l}\text { Elongation } \\
(\mathrm{mm})\end{array}$ & $\begin{array}{c}\text { Strain } \\
(\%)\end{array}$ \\
\hline 1 & 130 & 2.6 & 1.77 & 13.10 & 19.98 & 19.28 & 0.3213 \\
\hline 2 & 130 & 2.8 & 1.8 & 13.06 & 21.74 & 23.61 & 0.3935 \\
\hline 3 & 130 & 2.64 & 1.67 & 11.44 & 20.31 & 22.86 & 0.66 \\
\hline \multicolumn{2}{|c|}{ Ave } & 2.68 & 1.75 & 12.58 & 20.67 & 21.91 & 0.45 \\
\hline
\end{tabular}

The stress strain curve for the first sample is drawn based on the given and calculated value obtained in the test and shown in Figure 17

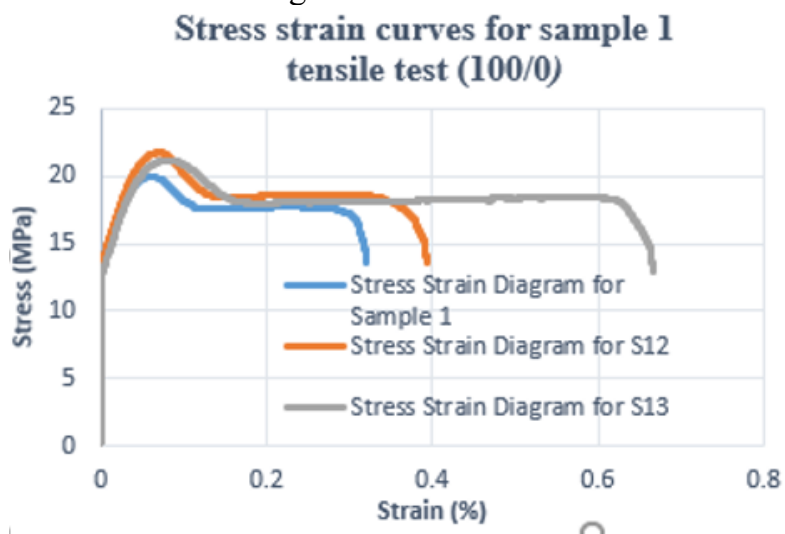

Fig. 17. vHDPE/rHDPE stress-strain curve for $100 / 0$ blends

The same methodology was applied to the $90 / 10,80 / 20$, $70 / 30,60 / 40,50 / 50,40 / 60,30 / 70,20 / / 80,10 / 90$, and $0 / 100 \mathrm{vHDPE} / \mathrm{rHDPE}$ ratio. Finally, all the specimen measured, and recorded results of tensile test were summarized as shown in Table 6, having all the obtained average results such as applying load, tensile strength, tensile stress, tensile strain, elongation and change in tensile strength from the virgin HDPE or reference material.

Figure 18 shows stress-strain diagram for all the test samples. This clearly shows the difference of how the strength of one sample is different from the others.

Table 6 shows the results from tensile strength of virgin HDPE (vHDPE) and recycled HDPE scraps (rHDPE) with different blend ratios. 
Table 6. Comparison of all tensile test results

\begin{tabular}{|c|c|c|c|c|c|c|c|c|}
\hline \multirow[b]{2}{*}{ 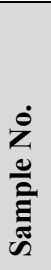 } & \multicolumn{8}{|c|}{ Tensile testing results } \\
\hline & $\begin{array}{l}\text { Composition ratio } \\
\text { (v:r) in (\%) }\end{array}$ & $\begin{array}{l}\text { Max. } \\
\text { Load } \\
(K N)\end{array}$ & $\begin{array}{l}\text { Load at } \\
\text { Brake (KN) }\end{array}$ & $\begin{array}{l}\text { Tensile } \\
\text { stress } \\
(M P a)\end{array}$ & $\begin{array}{l}\text { Yield } \\
\text { stress } \\
(M P a)\end{array}$ & $\begin{array}{l}\text { Tensile } \\
\text { strain }\end{array}$ & 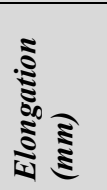 & $\begin{array}{l}\text { Change in } \\
\text { Tensile strength } \\
\text { (\%) }\end{array}$ \\
\hline 1 & 100:0 & 2.68 & 1.75 & 20.67 & 12.58 & 0.32 & 25.13 & 0 \\
\hline 2 & $90: 10$ & 2.6 & 1.7 & 20.03 & 12.01 & 0.47 & 28.01 & 3.10 \\
\hline 3 & $80: 20$ & 2.37 & 1.53 & 18.69 & 11.32 & 0.52 & 31.45 & 9.58 \\
\hline 4 & $70: 30$ & 2.35 & 1.45 & 18.16 & 11.04 & 0.55 & 33.23 & 12.14 \\
\hline 5 & $60: 40$ & 2.08 & 1.35 & 14.83 & 6.36 & 0.99 & 59.59 & 28.25 \\
\hline 6 & $50: 50$ & 1.65 & 1.02 & 12.68 & 5.67 & 0.65 & 38.71 & 38.65 \\
\hline 7 & $40: 60$ & 1.48 & 0.84 & 11.46 & 5.43 & 0.82 & 49.23 & 44.55 \\
\hline 8 & $30: 70$ & 1.32 & 0.72 & 10.19 & 5.11 & 0.43 & 26.29 & 50.70 \\
\hline 9 & $20: 80$ & 1.23 & 0.64 & 9.45 & 5.01 & 0.58 & 36.85 & 54.28 \\
\hline 10 & $10: 90$ & 1.16 & 0.61 & 8.96 & 4.56 & 0.72 & 39.77 & 56.65 \\
\hline 11 & $0: 100$ & 1 & 0.6 & 7.73 & 4.45 & 0.16 & 9.76 & 62.60 \\
\hline
\end{tabular}

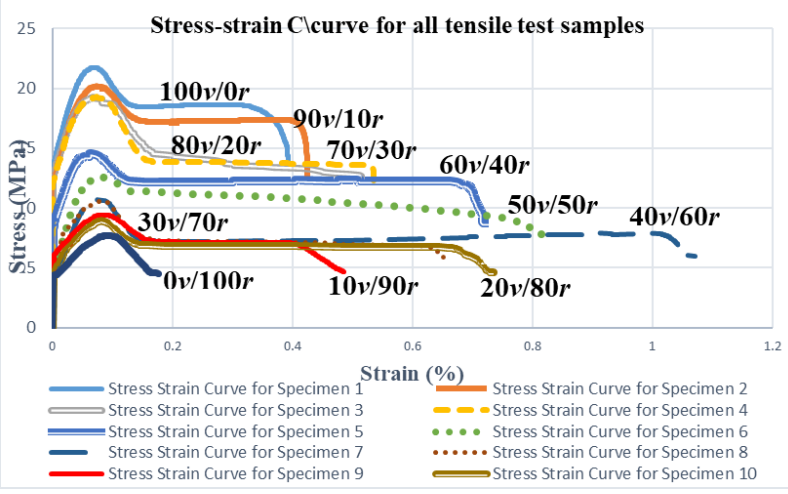

Fig. 18. Stress-strain curve for all tensile test samples

Table 6 shows the results from tensile strength of virgin HDPE (vHDPE) and recycled HDPE scraps (rHDPE) with different blend ratios. Eleven test samples were tested with different proportions $(100 / 0,90 / 10,80 / 20$, $70 / 30,60 / 40,50 / 50,40 / 60,30 / 70,20 / 80,10 / 90$, and $0 / 100$ virgin/recycled).

The tensile strength of vHDPE/rHDPE blends decreased with increasing rHDPE content. The reduced value of tensile strength of blend was due to the addition of rHDPE that influenced the strength of the blends. The $100 \%$ virgin HDPE has the highest yield strength (12.18 $\mathrm{N} / \mathrm{mm} 2$ ) when compared with that of the other ten (10) blended samples. The $100 \%$ recycled HDPE plastic sample has the lowest tensile strength

Maximum load, load at brake, yield strength and ultimate tensile strength of the samples also decreased as the addition of recycled HDPE material increases while in higher elongation or extension due to the amount of plasticizing effect of the initial present. However, it was observed that the melting temperature for each plastic type decreases with increase in the percentage of waste material.
Engineering stresses likely yield strength and ultimate tensile strength value between sample 1 and Sample 4 is a little bit as shown in Table 6. Samples made of 100 wt.\% virgin HDPE (100/0), 90 wt.\% virgin HDPE with 10 wt. $\%$ recycled HDPE scrap (90/10), 80 wt.\% virgin HDPE with 20 wt.\% recycled HDPE scrap (80/20), and 70 wt.\% virgin HDPE with 30 wt.\% recycled HDPE scrap (70/30) fulfilled the minimum standard requirement. While the remaining samples test results were a little bit smaller than minimum requirement i.e., From samples 5 to 11 or (60\% (virgin): $40 \%$ (recycled), $50 \%$ (virgin) :50 \% (recycled), $40 \%$ (virgin): $60 \%$ (recycled), $30 \%$ (virgin): $70 \%$ (recycled), $20 \%$ (virgin): $80 \%$ (recycled), $10 \%$ (virgin): $90 \%$ and $0 \%$ (virgin): $100 \%$ (recycled) blended sample is more pronounced strength different from the reference and under minimum requirement of the strength. It indicates that increasing in recycled material in the composition decreases the strength of the material due to lost in its material property.

The result obtained from this experimental data shows that, as the percentage of virgin HDPE material decreases, the tensile strength also decreases. This is because of the molecular weight of the material, i.e., in virgin materials, there are large molecular weight and strong bond strength. While in $100 \%$ recycled HDPE scraps, the bond strengths are weaker, due to different kinds of stress it has been subjected to during its previous usage when it is compared with other test results. Also, the water molecules absorption also increases, and this leaves space between bonding and subsequently the bond becomes weak, and strength is decreased in 100 wt.\% scraps. The 30 wt.\% recycled HDPE shows no significant problem on the strength. Therefore, $70 \mathrm{wt} . \%$ virgin and $30 \mathrm{wt} . \%$ proportion have shown optimum strength values. Generally, the mechanical property decrease as number of recycled contents are increased. Because, recycled high density 
polyethylene scrap (rHDPE) have weaker bond strength than virgin high density polyethylene (vHDPE) materials.

The purpose of this study is to find out the applicability of waste plastics of HDPE material blend and mix with compositions of virgin HDPE in order to determine the optimum strength from different composition samples and the effects of waste plastic in virgin HDPE. This has a great contribution to the eco-image of waste management and particularly to PSW recycling, treatment and recovery. Re-using and decreasing singlelife polymeric materials will certainly benefit the current situation. Consequently, recycling and using recycled materials is great importance to the economies and development of countries. It helps to reduce environmental pollution and the consumption of pure or virgin raw material.

\section{Conclusion}

Based on the obtained results, the following conclusions are deduced:

- The experimental analysis shows that it is possible to use recycled high-density polyethylene (rHDPE) scraps for pipe fitting production application is possible up to $30 \mathrm{wt} . \%$. Tensile strength test results indicate that addition up to $30 \mathrm{wt}$. \% scrap meet the standard requirement.

- With increasing recycling contents, the yield strength, ultimate tensile strength and the recovery percentage of the HDPE decrease while the percentage elongation slightly increases.

- Melt flow rate value fulfilled the minimum value accordance with ISO 1133 test methods for recycled high density polyethylene.

- By using 70\% vHDPE:30\% rHDPE composition, AG Pipe fitting Technology plc saves a lot of money per year. A mixing ratio of $70(\mathrm{~V})$ to $30(\mathrm{~W})$ is strongly suggested for these HDPE plastic types, since this offers the highest tensile strength for each type, and this will go a long way at reducing manufacturers cost without major effects on the main mechanical properties.

\section{References}

1. Ebewele RO. Polymer science and technology. CRC press; 2000 Mar 23.

2. Mohammadzadeh, Maryam. "Characterization of recycled thermoplastic polymers." (2009).

3. Benoit, Nathalie. "Mechanical recycling of high density polyethylene/flax fiber composites." (2017).

4. Chariyachotilert S, Kooudomrut N, Rittisith W. Agriculture and Natural Resources. 40, 166, (2006)

5. Dvorak, Maria. "Applicability of recycled HDPE for Rotational Molding." (2016).

6. Ingabire D, Ntihemuka F, Mugabo G, Isabane RS, Turatimana T. Rwanda Journal of Engineering, Science, Technology and Environment. 27, 1 (2018).

7. Fei NC, Kamaruddin S, Siddiquee AN, Khan ZA. Int J Mech Mater Eng. 6, 81(2011);6(1)
8. Lin JH, Pan YJ, Liu CF, Huang CL, Hsieh CT, Chen CK, Lin ZI, Lou CW. Materials. 8, 8850 (2015).

9. Achilias DS, Roupakias C, Megalokonomos P, Lappas AA, Antonakou EVJournal of hazardous materials. 149, 536 (2007).

10. Atikler U, Basalp D, Tihminlioğlu F. Journal of applied polymer science. 5, 4460 (2006)

11. Grigore ME. Recycling. 2, 24 ( 2017).

12. Evans, K., \& Russell, M. D., Nematologica, 39, 411 (1993)

13. Bajracharya RM, Manalo AC, Karunasena W, Lau KT. Effect of elevated temperature on the tensile properties of recycled mixed plastic waste ((ACMSM23) Southern Cross University 2014)

14. Sulyman M, Haponiuk J, Formela K. International Journal of Environmental Science and Development. 7(2), 100 (2016).

15. Hamad K, Kaseem M, Deri F., Polymer degradation and stability. 98, 2801 (2013).

16. Mamoor GM, Shahid W, Mushtaq A, Amjad U, Mehmood U. Chemical Engineering Research Bulletin. 16(1), 25 (2013)

17. Loultcheva MK, Proietto M, Jilov N, La Mantia FP. Polymer degradation and stability. 57, 17 (1997)

18. La Mantia FP. InFrontiers in the Science and Technology of Polymer Recycling, 371(1998)

19. Ragaert K, Delva L, Van Geem K., Waste management. 69, 24 (2017).

20. Rybicka J, Tiwari A, Leeke GA. Technology readiness level assessment of composites recycling technologies. Journal of Cleaner Production. 112, 1001(2016). 